\title{
A synthesis of a blade pitch control for large wind turbines, taking into account the functional dependence of the torque generated in the blades from the azimuth angle
}

\author{
Julian Genov ${ }^{1, *}$ \\ ${ }^{1}$ Technical University - Sofia, Department of Mechanics, 8 Kl. Ohridski Blvd., 1000 Sofia, Bulgaria
}

\begin{abstract}
In multi-MW (1MW and up) wind generation systems a variable speed - variable pitch (VS-VP) control technology is usually adopted to improve speed and torque characteristics and to obtain the optimal energy, which means to obtain the maximum power at low wind speed and the rated power at high wind speed. The power generated by an individual blade of the wind turbine changes considerably during rotation due for the change of wind speed in vertical direction, which decreases the angles of attack in the low blade positions and which leads to a reducing the generated energy. In the paper basing on BEM theory modification for none-homogenously fluid field and an optimization procedure is obtained an individual variable pitch control law as function of wind speed values and blades positions.
\end{abstract}

\section{Introduction}

The vertical speed gradient leads to significant changes of the torque generated from one blade during rotation. This is due to the fact that in the lower blade positions the wind speed decreases considerable, this leads to reducing the angles of attack and as a result of this, the torque diminishes. Therefore, if an individual blade pitch control is applied, it is possible to increase power to a certain extent, especially for wind speeds below the nominal. The determination of this control is complicated because the blades are building from sections with different profile and respectively different lift and drag coefficients. Thus if the angle of attack exceeded a certain value the aerodynamic interaction may get worse. Moreover due to the continuity of the fluid flow, the induction coefficients are in dependence with aerodynamic state of all blades, which is a prerequisite for additional complexity in determination of the optimum angle of attack in the given position of the blade. For a solution of this problem, basing on the adaptation of the classical blade element momentum (BEM) theory to the accounting of the vertical gradient of the wind speed, in this research an optimization approach for the determination of the individual pitch control law is proposed. The approach is realised for a set of discrete positions of the turbine and then the control dependence is obtained of by interpolation between them. The obtained results for a known prototype of wind turbine show simultaneously the validity of the BEM theory modification and of the propose approach for synthesis of an individual blade pitch control.

\section{Pitch control synthesis}

In [1-9] is investigated a pitch control synthesis that provided efficiency and high quality of produced electricity as well as maintaining the lowest possible dynamic loads in some elements of the wind generator's system.

In present paper this synthesis is treated in an aspect of obtaining both the maximum power at lower than the nominal wind speeds and the rated power at higher then nominal wind speeds, taking in account the fluid speed gradient in vertical direction. For the first purpose is investigated an individual form of pitch angle control and for the second is using collective pitch control form.

\subsection{Wind speed distribution}

The proposed algorithm is presented for the prototype wind turbine of high class - NREL5MW [10]. For the vertical wind speed distribution is preferred the logarithmic model [11]. For the parameters values defined in [12], the wind distribution as a function of the speed in the hub axis at a height of $90 \mathrm{~m}$, and height $\mathrm{z}$ has the form:

$$
v_{\infty}(z)=0,059 v_{\infty}(z=90)\left[\ln \left(\frac{z-0,138}{0,03}\right)+0,1 z\right], \frac{m}{s}
$$

On Fig. 1 are shown vertical distributions for in the hub axis wind speeds: $3 \div 10,10.5,11,11.4 \mathrm{~m} / \mathrm{s}$.

* Corresponding author: j_genov@mail.org 


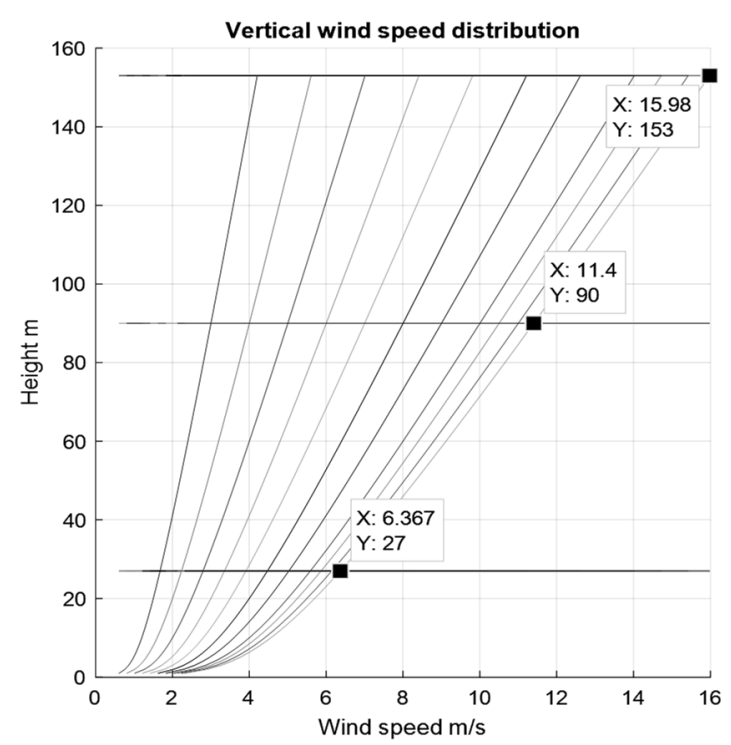

Fig. 1. Vertical distribution of wind speed.

\subsection{BEM theory adaptation with taking in account the vertical wind speed gradient}

The BEM theory is presented in many sources [13-23]. In the most of them the fluid field is considered as a homogeneous i.e. the differences of the wind speed in a vertical direction are neglected. Thus for all blades, the dynamic interaction with the wind flow is an identical and does not depend on the azimuth angle. For the turbines with standard size this is acceptable but for the high class it is observes significant different of the vertical speed distribution in the turbine disk. This causes that, for the given position each of the blades have a considerably different aerodynamic interaction with the wind. Respectively the aerodynamic forces that act on the blade become a function of the blade azimuth angle and varying even if the longitudinal turbulence of the wind velocity is not considered. The common used methodology for calculation of induction coefficients is needs to be revision. In [14, 16-19, 21, 23] some semi-analytical or numerical investigations in this or similar sense are made.

In the next text are presented the results obtained by the author in adaptation of BEM theory for the case of nonhomogeneous vertical wind speed distribution.

On Fig. 2 are shown the elements of the aerodynamic excitations in the plane of the blade cross-section.

The designations shown in the figure are as follows: $r$ - distance from the hub axes;

$\varphi_{w t}$ - blade azimuth angle (zero in vertical upward direction);

$\omega_{w t}=\dot{\varphi}_{w t}-$ angular velocity of the turbine rotation;

$v_{\infty}\left(\varphi_{w t}, r\right)$ - inflow speed; $v_{\mathrm{d}}\left(\varphi_{w t}, r\right)$ - flow speed in turbine disk;

$v_{b}\left(\varphi_{w t}, r\right)=r \omega_{w t}\left(1+a^{\prime}\left(\varphi_{w t}, r\right)\right)-$ tangential component of the relative flow velocity for the section;

$v_{r e l}\left(\varphi_{w t}, r\right)=\frac{\left(1-a\left(\varphi_{w t}, r\right)\right)}{\sin \left(\phi\left(\varphi_{w t}, r\right)\right)} v_{\infty}\left(\varphi_{w t}, r\right)-$ relative (effective) flow velocity;

$a=\left(v_{\infty}-v_{d}\right) / v_{\infty}-$ axial induction factor; $a^{\prime}=0,5 \omega_{d} / \omega_{w t}-$ tangential induction factor;

$\omega_{d}$ - angular velocity of the flow in the disk plane;

$\beta\left(\varphi_{w t}, r\right)=\beta_{c}\left(\varphi_{w t}\right)+\beta_{0}(r)$ - section pitch angle;

$\beta_{0}(r)$ - construction pitch angle for the section;

$\beta_{c}\left(\varphi_{w t}\right)$-blade pitch angle set by the system of the active control;

$\phi\left(\varphi_{w t}, r\right)=\operatorname{arctg}\left(v_{d}\left(\varphi_{w t}, r\right) / v_{b}\left(\varphi_{w t}, r\right)\right) \quad-\quad$ inflow angle for the section;

$\alpha\left(\varphi_{w t}, r\right)=\phi\left(\varphi_{w t}, r\right)-\beta\left(\varphi_{w t}, r\right)-$ angle of an attack; $F_{\text {Torque }}\left(\varphi_{w t}, r\right)$ - torque force, $F_{\text {Thrust }}\left(\varphi_{w t}, r\right)$ - thrust forces, $M_{w t}\left(\varphi_{w t}, r\right)$ - torque

$C_{\text {Torque }}, C_{\text {Thrust }}, C_{L}, C_{D}$ - torque, thrust, lift and drag coefficients of the section.

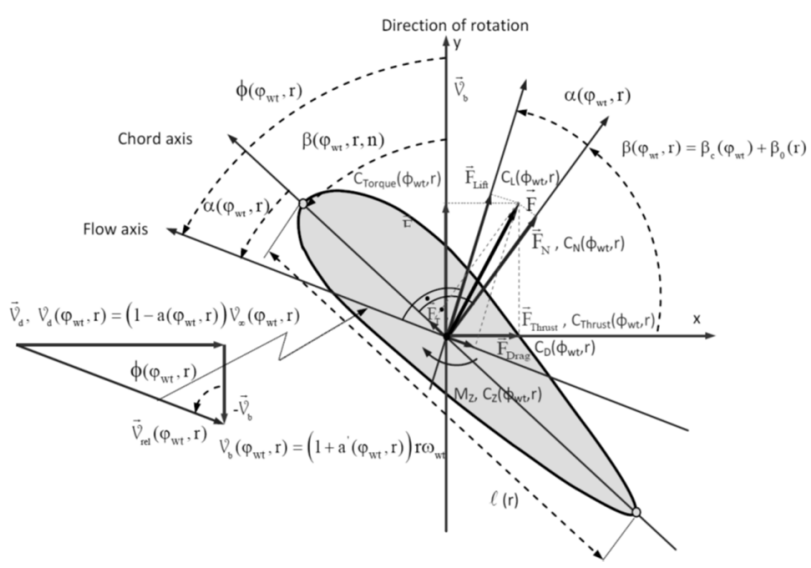

Fig. 2. Wind stream and induced forces acting on blade elements.

The following dependencies are in effect:

$$
\begin{aligned}
& F_{\text {Thrust }}\left(\varphi_{w t}, r\right)=C_{\text {Thrust }}\left(\varphi_{w t}, r\right) F\left(\varphi_{w t}, r\right) \\
& F_{\text {Torque }}\left(\varphi_{w t}, r\right)=C_{\text {Torque }}\left(\varphi_{w t}, r\right) F\left(\varphi_{w t}, r\right)
\end{aligned}
$$

where:

$$
\begin{array}{r}
F\left(\varphi_{w t}, r\right)=0,5 \rho \ell_{T}(r) v_{r e l}^{2}\left(\varphi_{w t}, r\right) F_{c}\left(\varphi_{w t}, r\right) ; \\
C_{\text {Thrust }}\left(\varphi_{w t}, r\right)=C_{L}\left(\alpha\left(\varphi_{w t}, r\right)\right) \cos \left(\phi\left(\varphi_{w t}, r\right)\right)+ \\
+C_{D}\left(\alpha\left(\varphi_{w t}, r\right)\right) \sin \left(\phi\left(\varphi_{w t}, r\right)\right) ; \\
C_{\text {Torque }}\left(\varphi_{w t}, r\right)=C_{L}\left(\alpha\left(\varphi_{w t}, r\right)\right) \sin \left(\phi\left(\varphi_{w t}, r\right)\right)- \\
-C_{D}\left(\alpha\left(\varphi_{w t}, r\right)\right) \cos \left(\phi\left(\varphi_{w t}, r\right)\right),
\end{array}
$$

$\ell_{T}\left(\varphi_{w t}, r\right)=\ell(r) \cos \left(\beta\left(\varphi_{w t}, r\right)\right)$ - projection of the chord of the blade cross-section $\ell(r)$,

$F_{c}=F_{T L} F_{R o o t}-$ flow correction factor [20],

$F_{T L}=\frac{2}{\pi} \arccos \left(\mathrm{e}^{-\frac{\mathrm{N}}{2 \sin (\phi)}\left(\frac{\mathrm{R}}{\mathrm{r}}-1\right)}\right)-$ Tip-Loss Prandtl-Glauert correction;

$F_{\text {Root }}=\frac{2}{\pi} \arccos \left(e^{-\frac{N}{2 \sin (\phi)}\left(1-\frac{R_{H} u b}{r}\right)}\right) \quad-$ is a correction that considers the vortices at the blade's base around the turbine hub;

$N$ is the number of the blades;

$R_{H u b}$ is the hub radius.

For the blade, it is obtained:

$$
\begin{gathered}
F_{\text {Thrust }}\left(\varphi_{w t}\right)= \\
=0,5 \rho \int_{r=R_{H u b}}^{R} \ell_{T}\left(\varphi_{w t}, r\right)\left(1-a\left(\varphi_{w t}, r\right)\right)^{2} K_{\text {Thrust }}\left(\varphi_{w t}, r\right) d r
\end{gathered}
$$


$M_{w t}\left(\varphi_{w t}\right)=$

$0,5 \rho \int_{r=R_{\text {Hub }}}^{R} \ell_{T}\left(\varphi_{w t}, r\right)\left(1-a\left(\varphi_{w t}, r\right)\right)^{2} r K_{\text {Torque }}\left(\varphi_{w t}, r\right) d r$

where:

$K_{\text {Thrust }}\left(\varphi_{w t}, r\right)=\sum_{i=1}^{N}\left[C_{L}\left(\alpha\left(\varphi_{i}, r\right)\right) \operatorname{cotg}\left(\phi\left(\varphi_{i}, r\right)\right)+\right.$ $\left.+C_{D}\left(\alpha\left(\varphi_{i}, r\right)\right)\right] \Upsilon\left(\varphi_{i}, r\right)$;

$K_{\text {Torque }}\left(\varphi_{w t}, r\right)=\sum_{i=1}^{N}\left[C_{L}\left(\alpha\left(\varphi_{i}, r\right)\right)-\right.$

$\left.-\operatorname{cotg}\left(\phi\left(\varphi_{i}, r\right)\right) C_{D}\left(\alpha\left(\varphi_{i}, r\right)\right)\right] \curlyvee\left(\varphi_{i}, r\right)$;

$\Upsilon\left(\varphi_{i}, r\right)=\frac{v_{\infty}^{2}\left(\varphi_{i}, r\right) F_{C}\left(\varphi_{i}, r\right)}{\sin \left(\phi\left(\varphi_{i}, r\right)\right)}$.

The induction factors are:

$\mid \begin{aligned} & a\left(\varphi_{w t}, r\right)=\frac{K\left(\varphi_{w t}, r\right)}{1+K\left(\varphi_{w t}, r\right)} \\ & a^{\prime}\left(\varphi_{w t}, r\right)=\frac{\omega_{d}\left(\varphi_{w t}, r\right)}{2 \omega_{w t}}=\frac{K_{\text {Torque }}\left(\varphi_{w t}, r\right)}{\tilde{\lambda}(r) K_{\text {Thrust }}\left(\varphi_{w t}, r\right)} a\left(\varphi_{w t}, r\right)\end{aligned}$

where:

$K\left(\varphi_{w t}, r\right)=\frac{\ell_{T}\left(\varphi_{w t}, r\right)}{4 r \int_{\gamma=0}^{2 \pi} \mathrm{V}_{\infty}{ }^{2}(r, \gamma) d \gamma} K_{\text {Thrust }}\left(\varphi_{w t}, r\right)$,

$\tilde{\lambda}(r)=r \omega_{w t} \int_{\gamma=0}^{2 \pi} \mathrm{V}_{\infty}(r, \gamma) d \gamma / \int_{\gamma=0}^{2 \pi} \mathrm{V}_{\infty}{ }^{2}(r, \gamma) d \gamma$.

\subsection{Obtaining of pitch control law}

The relation between torque and angular velocity of the turbine is shown of Fig. 3.

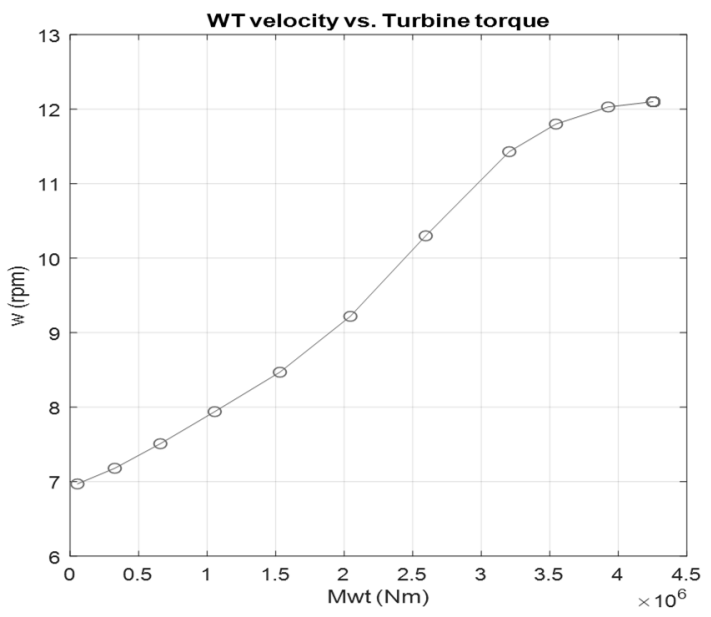

Fig. 3. Relation between torque and angular velocity of the turbine

The results, from the numerical modelling, for the angular turbine velocities $\omega_{w t r}$, average thrust force $F_{\text {Thrust }}^{a v}$, torque $-M_{w t}^{a v}$ and power $-P_{w t}^{a v}$ values, without using pitch control, obtained for values between the minimal and nominal wind velocity, related to the hub axis level $-v_{\infty}^{H u b}$, are shown in Table 1 .

The proposed control law is individual pitch for wind velocity under the nominal value and collective for over the nominal.

The pitch angle has two components:

$$
\beta\left(\varphi_{w t}, r\right)=\beta_{c}\left(\varphi_{w t}\right)+\beta_{0}(r)
$$

where: $\beta_{0}(r)$ is the construction pitch angle for the blade section;

$\beta_{c}\left(\varphi_{w t}\right)$ blade pitch angle set by the system for active pitch control.

Table 1. The results from the modelling without pitch control

\begin{tabular}{|c|c|c|c|c|}
\hline$v_{\infty}^{\text {Hub }}$ & $\omega_{w t r}$ & $F_{\text {Thrust }}^{a v}$ & $M_{w t}^{a v}$ & $P_{w t}^{a v}$ \\
\hline $\mathrm{m} / \mathrm{s}$ & $\mathrm{tr} / \mathrm{min}$ & $\mathrm{kN}$ & $\mathrm{MNm}$ & $\mathrm{MW}$ \\
\hline 3 & 6.97 & 37.0 & 0.053241 & 0.038860 \\
\hline 4 & 7.18 & 106.7 & 0.325716 & 0.244902 \\
\hline 5 & 7.51 & 154.4 & 0.658100 & 0.517560 \\
\hline 6 & 7.94 & 206.7 & 1.054802 & 0.877041 \\
\hline 7 & 8.47 & 262.2 & 1.530413 & 1.357440 \\
\hline 8 & 9.22 & 329.7 & 2.044856 & 1.974342 \\
\hline 9 & 10.30 & 415.0 & 2.594580 & 2.798549 \\
\hline 10 & 11.43 & 511.8 & 3.204408 & 3.835507 \\
\hline 10.5 & 11.80 & 558.0 & 3.544856 & 4.380354 \\
\hline 11 & 11.99 & 598.5 & 3.925783 & 4.945617 \\
\hline 11.4 & 12.10 & 625.6 & 4.254310 & 5.390675 \\
\hline
\end{tabular}

The torque of the blade elements as function of the azimuth angle and the element position by the length of the blade for the different wind speed from 3 to $25 \mathrm{~m} / \mathrm{s}$ is shown of Fig. 4.

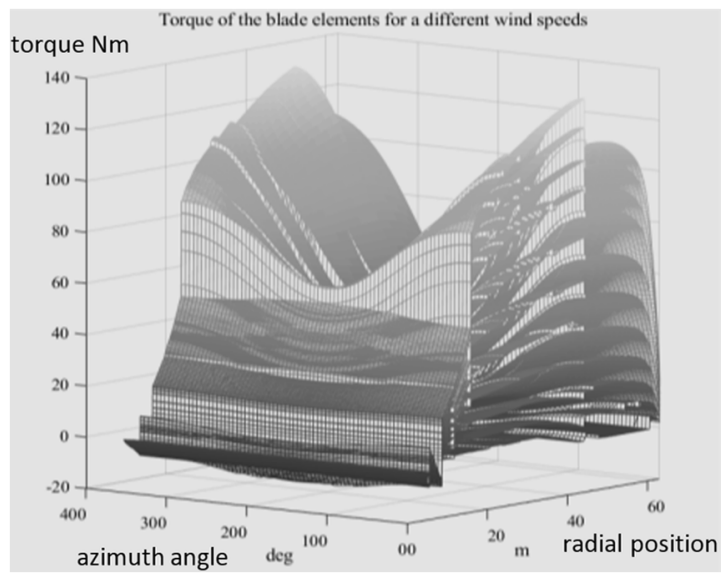

Fig. 4. Torque of the blade elements as function of the blade azimuth angle and the element position for wind speed from 3 to $25 \mathrm{~m} / \mathrm{s}$, without using pitch control.

By using the described models of the wind and of the aerodynamic interaction, for fixed azimuth angles $\varphi_{w t i}=0^{\circ}, 30^{\circ}$ and $60^{\circ}$ measured from the upper vertical position, an optimization procedure is used applied for all discrete values of the wind velocities $v_{\infty_{j}}$ in the working range from 3 to $25 \mathrm{~m} / \mathrm{s}$.

The object functions for the velocities under the nominal are defined by mean of the wind turbine torque for the corresponding discrete angle of rotation $\varphi_{\text {wti }}$. The procedures of optimization are realized consecutively for three of the positions of the turbine:

$$
\varphi_{w t_{1}}=0^{0}, \varphi_{w t_{2}}=30^{0}, \varphi_{w t_{3}}=60^{\circ},
$$

and for these positions, as an optimization parameters are obtain the pitch control angles of the three blades:

$$
\beta_{i, 1}, \beta_{i, 2}, \beta_{i, 3}, \text { for } \varphi_{w t_{\mathrm{i}}}, \mathrm{i}=1,2,3,
$$


witch maximise the turbine torque at the corresponding position.

This is repeated for all discrete values of the wind speed referred on level of turbine axis $-v_{\infty}^{H u b}$ :

$$
3 \div 10 ; 10,4 ; 11 ; 11,4 \mathrm{~m} / \mathrm{s} \text {. }
$$

The used constraints for the optimization parameters are of the type Lower-Upper boundaries.

In this way the optimization can be described mathematically as:

$$
\begin{gathered}
\left.\left\{J_{i}\left(\mathbf{X}_{i}\right)=\max _{X_{i} \in D} M_{w t}\left(\varphi_{w t_{i}}, v_{\infty_{j}}, \mathbf{X}_{i}\right), \mathrm{i}=1,2,3\right\}\right|_{j=1, . .11} \\
\mathbf{X}_{i}=\left[\beta_{i, 1}, \beta_{i, 2}, \beta_{i, 3}\right], \\
\mathrm{D}=\left\{\mathbf{X} \in \mid \mathbf{X}_{i}^{\text {Lower }} \leq \mathbf{X} \leq \mathbf{X}_{i}^{\text {Upper }}\right\} \in \mathrm{P}_{\leq 0}^{3} \\
\left.\varphi_{w t_{i}}\right|_{i=1,2,2} \in\left\{\varphi_{w t_{1}}=0^{0}, \varphi_{w t_{2}}=30^{0}, \varphi_{w t_{3}}=60^{0}\right\} \\
v_{\infty_{j}} \in\{3 \div 10 ; 10,4 ; 11 ; 11,4\} \mathrm{m} / \mathrm{s} .
\end{gathered}
$$

The pitch control angles values in the other positions in the turbine disk, located through 30 degrees, are obtained taking in an account theirs symmetry relative to the aerodynamic interaction. Then through a polynomial interpolation of the obtaining data for these discrete positions, are calculated the pitch angles values of the blades, for any other intermediate turbine position.

The object functions, for the all velocities of the wind over the nominal, is referred to the condition that the average values of the torques for a one full rotation of the turbine $M_{w t}^{a v}$ should be equal to the nominal value of 4.25431 MNm (see Table 1). In this case the optimized parameter is the collective pitch angle, which is not treated as function of the azimuth angle and it is only a function of the wind speed. The mathematical presentation of this optimization task is:

$$
\begin{gathered}
J_{j}\left(\beta_{j}\right)=\left.\min _{\beta_{i} \in D}\left|M_{w t}\left(v_{\infty_{j}}, \beta_{j}\right)-M_{w t}\left(v_{\infty}^{\mathrm{n}}, 0\right)\right|\right|_{j=12, . .25} \\
\mathrm{D}=\left\{\beta \in \mid 0 \leq \beta \leq \beta_{j}^{\text {Upper }}\right\} \in \mathrm{P}_{\geq 0} \\
v_{\infty_{j}} \in\{12,13, . .25\} \mathrm{m} / \mathrm{s} .
\end{gathered}
$$

The optimization is realised by the Quasi-Monte Carlo method based on the using of the Sobol sequences [24]. It is generated cover of 150 points in the definition area, for each position. This number of points proves to be sufficient for the localization of the optimum.

The obtained results are given in Table 2 .
Table 2. Results of modeling with pitch control individual for wind velocity under the nominal value and collective for over the nominal.

\begin{tabular}{|c|c|c|c|c|c|}
\hline$v_{\infty}$ & Pitch angle $\beta$ & $\omega_{w t}$ & $F_{\text {Thrust }}^{a v}$ & $M_{w t}^{a v}$ & $\mathrm{P}_{w t}^{a v}$ \\
\hline $\mathrm{m} / \mathrm{s}$ & deg & tr/min & $\mathrm{kN}$ & $\mathrm{MNm}$ & $\mathrm{MW}$ \\
\hline 3 & $\begin{array}{c}\text { polynomial } \\
\text { approximation }\end{array}$ & 6.97 & 37.0 & 0.057231 & 0.0389 \\
\hline 4 & $--/ /--$ & 7.18 & 106.7 & 0.395435 & 0.2449 \\
\hline 5 & $--/ /--$ & 7.51 & 154.4 & 0.7242781 & 0.5176 \\
\hline 6 & $--/ /--$ & 8.00 & 238.6 & 1.105343 & 0.9254 \\
\hline 7 & $--/ /--$ & 8.54 & 306.9 & 1.584803 & 1.4169 \\
\hline 8 & $--/ /--$ & 9.37 & 385.1 & 2.128162 & 2.0880 \\
\hline 9 & $--/ /--$ & 10.53 & 483.0 & 2.703402 & 2.9800 \\
\hline 10 & $--/ /--$ & 11.6 & 594.0 & 3.338278 & 4.0550 \\
\hline 10,5 & $--/ /--$ & 11.92 & 564.1 & 3.708268 & 4.6285 \\
\hline 11 & $--/ /--$ & 12.08 & 691.5 & 4.105221 & 5.1942 \\
\hline 11,4 & 0,00 & 12.10 & 625.6 & 4.254310 & 5.3907 \\
\hline 12 & 2,75 & 12.10 & 542.5 & 4.254371 & 5.3908 \\
\hline 13 & 5,51 & 12.10 & 471.3 & 4.255132 & 5.3917 \\
\hline 14 & 7,66 & 12.10 & 419.4 & 4.253839 & 5.3901 \\
\hline 15 & 9,48 & 12.10 & 380.4 & 4.255933 & 5.3927 \\
\hline 16 & 11,13 & 12.10 & 348.5 & 4.254364 & 5.3907 \\
\hline 17 & 12,64 & 12.10 & 322.7 & 4.256122 & 5.3930 \\
\hline 18 & 14,07 & 12.10 & 299.8 & 4.250831 & 5.3863 \\
\hline 19 & 15,42 & 12.10 & 280.5 & 4.251241 & 5.3868 \\
\hline 20 & 16,71 & 12.10 & 263.6 & 4.252468 & 5.3883 \\
\hline 21 & 17,95 & 12.10 & 248.7 & 4.252856 & 5.3888 \\
\hline 22 & 19,14 & 12.10 & 235.5 & 4.257366 & 5.3946 \\
\hline 23 & 20,30 & 12.10 & 223.3 & 4.253881 & 5.3901 \\
\hline 24 & 21,42 & 12.10 & 212.4 & 4.254932 & 5.3915 \\
\hline 25 & 22,51 & 12.10 & 202.6 & 4.254687 & 5.3912 \\
\hline & & & & & \\
\hline
\end{tabular}

The individual pitch control as function of the blade azimuth angle, for different wind speeds is shown on Fig. 5.

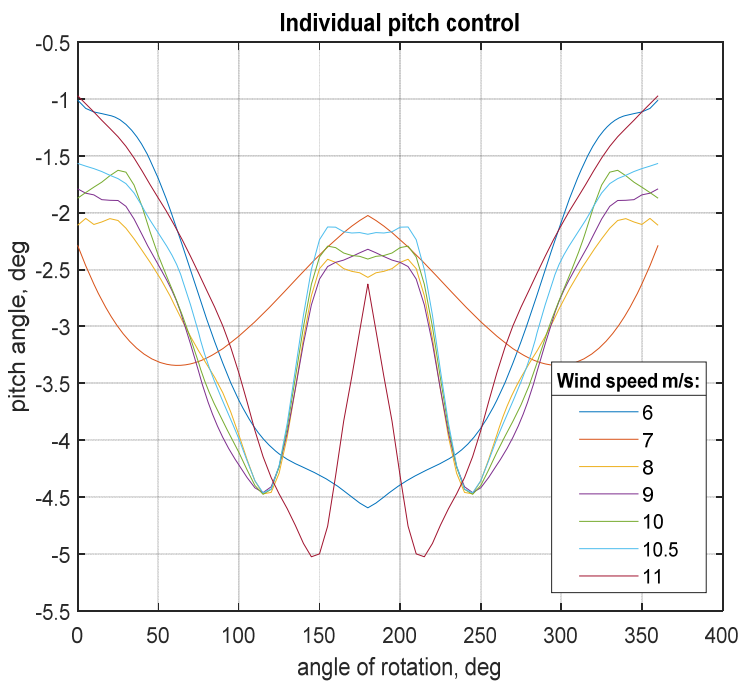

Fig. 5. Individual pitch control as function of angle of the turbine rotation.

The collective pitch control as function of the wind speeds on the level of the hub axis is shown on Fig. 6 . 


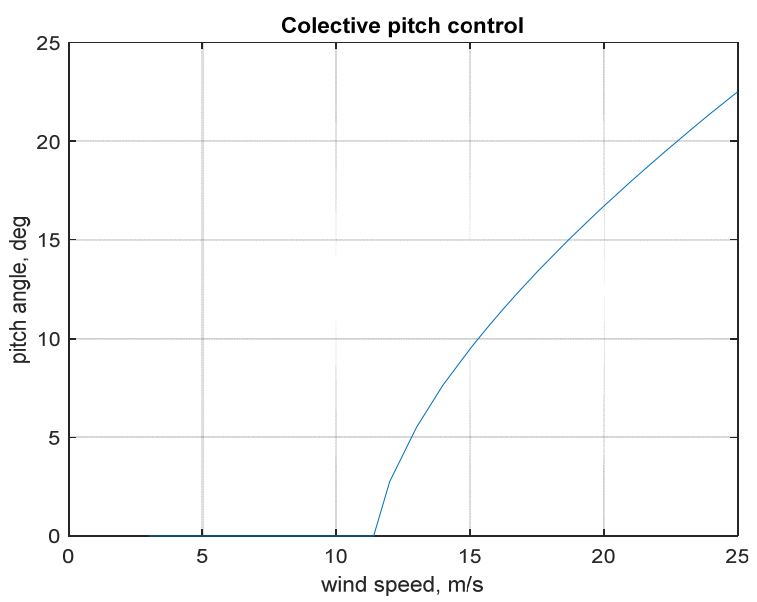

Fig. 6. Collective pitch control as function of the wind speed on the level of the turbine axis.

The pitch control as function of the wind speed at the level of hub axis and the angle of blade azimuth is shown on Fig. 7.

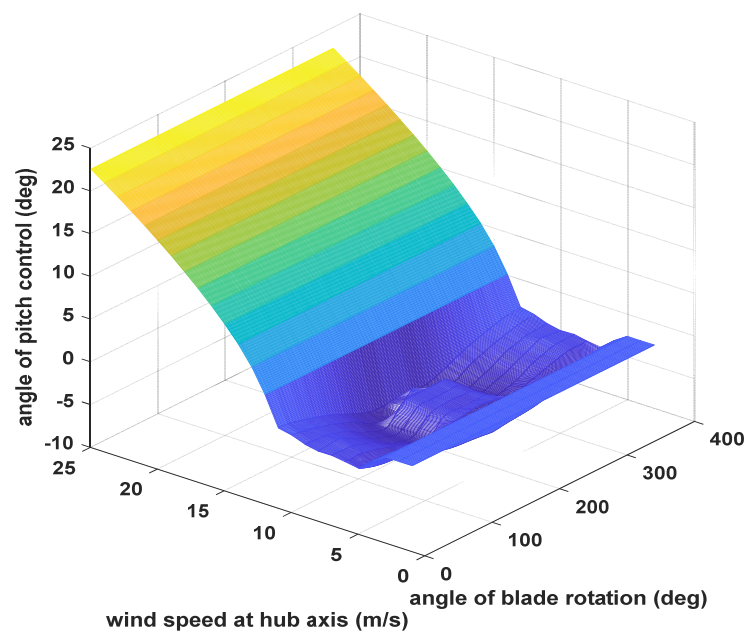

Fig. 7. Pitch control as function of the wind speed and the angle of blade rotation.

On Fig. 8 is shown the turbine power with and without pitch control and on Fig. 9 the thrust forces of the blade elements as function of the azimuth angle and the element position by the length of the blade for the different wind speed in range from 3 to $25 \mathrm{~m} / \mathrm{s}$.

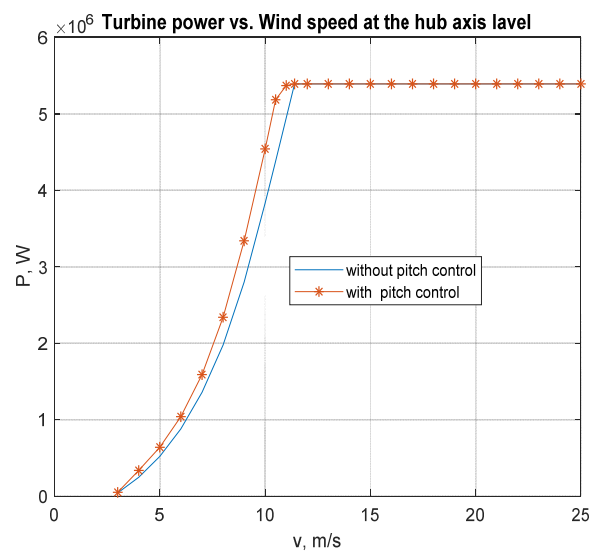

Fig. 8. Turbine power without and with proposed pitch control.

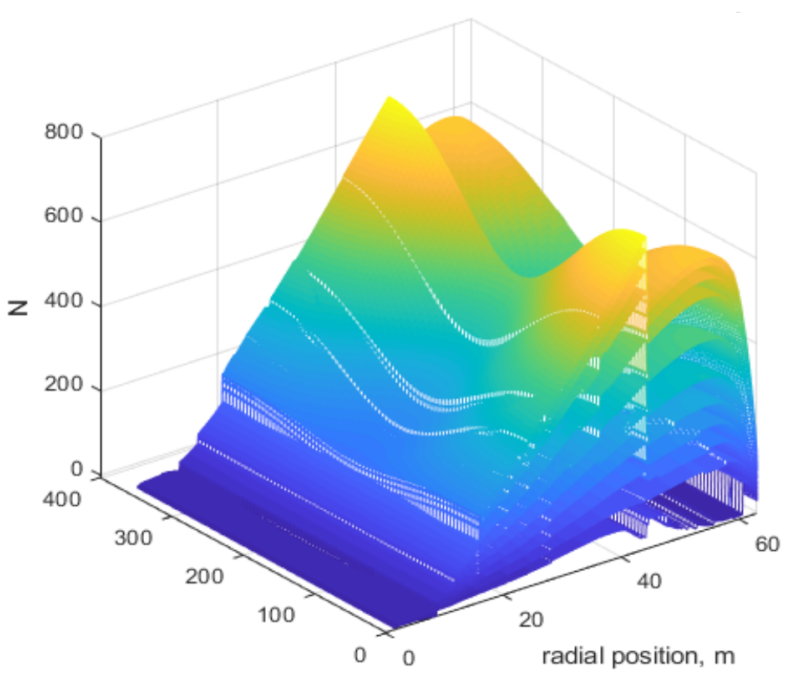

blade azimuth angle, deg

Fig. 9. Thrust forces of the blade elements as function of the azimuth angle and the element position for wind speed from 3 to $25 \mathrm{~m} / \mathrm{s}$, with using pitch control.

This is not very large, but is a tangible improvement of the power characteristics.

\section{Conclusion}

The paper presents an optimal synthesis of a new type pitch control of the wind turbines of high class that takes into account the effects due to the vertical gradient of the wind velocity. It is based on proposed modification of BEM theory. The obtained from the simulation results show that they are some better in comparison of these without of such type control. The theory may to be applied ease for the synthesis of the blade pitch control when the longitudinal turbulence of the wind velocity is also included in the model.

\section{References}

1. E. Hooft; P. Schaak; T. Engelen, Wind turbine control algorithms, DOWEC-F1W1-EH-03-094/0, Petten, Nederland (2003)

2. M. Hansen, A. Hansen, T. Larsen, S. Øye, P. Sørensen, P. Fuglsang, Control design for a pitchregulated, variable speed wind turbine, Risø National Laboratory Information Service Department, Denmark, 85 (2005)

3. K. Stol, W. Zhao, Al. Wright, Individual blade pitch control for the controls advanced research turbine, Transactions of the ASME Journal of Solar Energy Engineering, 128, 498-505 (2006)

4. F. Bianchi, H. Battista, R. Mantz, Wind turbine control systems principles - Modelling and gain scheduling design, 205 (Springer-Verlag London Ltd., 2007)

5. I. Munteanu, A. Bratcu, N. Cutululis, E. Ceanga, Optimal control of wind energy systems - Towards a global approach, 283 (Springer-Verlag London Ltd., 2008) 
6. A. Wright, L. Fingersh, Advanced control design for wind turbines Part I: Control design, implementation, and initial tests, Technical Report NREL/TP-50042437, U.S. Department of Energy, 148 (2008)

7. C. Bottasso, A. Croce, Advanced control laws for variable-speed wind turbines and supporting enabling technologies, Scientific Report DIA-SR 09-01, Dept. of Aerospace Engineering, Polytechnics of Milano, 41 (2009)

8. J. Genov et al., Modeling and control of wind turbine tower vibrations, AIP Conference Proceedings, 1293(1), 30-38 (2010)

9. J. Genov, G. Venkov, B. Gilev, Modeling and control of a wind turbine, Information Technologies and Control, 2, 15-22 (2012)

10. J. Jonkman, S. Butterfield, W. Musial, G. Scott, Definition of a 5-MW reference wind turbine for offshore system development, Technical Report NREL/TP-500-38060, 75 (2009)

11. L. Landberg, Meteorology for wind energy - an introduction, (John Wiley \& Sons Ltd., 2016)

12. J. Genov, I. Angelov, Influence of the vertical wind speed distribution on the dynamic load of wind turbines of high class (in bulgarian), BulTrans-2016 Proceedings, 136-140 (2016)

13. W. Rankine, W. Froude, On the mechanical principles of the action of propellers, Transactions of the Institution of Naval Architects, 6, 13-39 (1865)

14. R. Wilson, P. Lissaman, Applied aerodynamics of wind power machines, National Science Foundation, Oregon State University, USA, 109 (1974)

15. J. Anderson, Fundamentals of aerodynamics, (McGraw-Hill Inc., 1991)

16. J. Conway, Analytical solutions for the actuator disc with variable radial distribution of load, J. Fluid Mech., 297, 327-355 (1995)

17. J. Conway, Exact actuator disk solutions for nonuniform heavy loading and slipstream contraction, J. Fluid Mech., 356, 235-267 (1998)

18. T. Wang, Unsteady aerodynamic modelling of horizontal axis wind turbine performance, $\mathrm{PhD}$ Dissertation, University of Glasgow, 299 (1999)

19. R. Bontempo, The nonlinear actuator disk method as applied to open and ducted rotors, PhD Dissertation, University of Naples Federico II, 153 (2014)

20. M. Hansen, Aerodynamics of wind turbines - Third edition, 187 (Taylor\&Francis Group, 2015)

21. T. Sant, Improving BEM-based aerodynamic models in wind turbine design codes, $\mathrm{PhD}$ Dissertation, Delft University - Wind Energy Institute, 447 (2007)

22. P. Jamieson, Innovation in wind turbine design, 297 (John Wiley \& Sons Ltd., 2011)

23. Cv. Velkova, J. Minchev, Numerical flow simulation of a SCREW propeller, Machines Mechanics, ISSN 0861-9727, 118, 1-7 (2017)
24. I. Sobol, Uniformly distributed sequences with an addition uniform property, USSR Computation Maths. Math. Phys., 16, 236-242 (1976) 